Arab World English Journal (AWEJ) Volume 12. Number2 June 2021

DOI: https://dx.doi.org/10.24093/awej/vol12no2.7

\title{
Synchronous and Asynchronous English Writing Classes in the EFL Context: Students' Practices and Benefits
}

\author{
Nada Bin Dahmash \\ College of Applied Studies and Community Service \\ King Saud University, Riyadh, Saudi Arabia
}

Received: 3/3/2021

Accepted: 4/29/2021

Published:6/24/2021

\begin{abstract}
Synchronous and asynchronous classes were implemented by universities around the world during the COVID-19 pandemic. Students learning English as a Foreign Language (EFL) engaged in multiple practices when attending English writing classes in both modes. However, the practices they engaged in and the benefits they perceived were reportedly of limited benefit. This study asks: What are the practices of students that emerge during synchronous and asynchronous English writing classes? What are the benefits of synchronous and asynchronous English writing classes from the student's perspective? Group and one-to-one interviews were conducted with twelve students majoring in computer science and information technology at a Saudi university. Thematic analysis revealed that students engage in practices including using the split view on iPads, opening additional windows to search for information, searching using smartphone apps, and writing notes and highlighting key concepts when attending English writing classes regardless of learning mode. It also revealed that synchronous classes offered students real-time communication and provided immediate feedback, while asynchronous classes allowed students to navigate the challenges of distance learning, complementing the synchronous English writing classes and providing students with a sense of security. This paper concludes by advising language teachers to record synchronous classes, raise students' awareness of the benefits of attending both types of classes and encourage students to apply practices reported by previous students to maximize their English language learning.

Keywords: asynchronous class, benefits, English writing, practices, synchronous class

Cite as: Bin Dahmash, N. (2021). Synchronous and Asynchronous English Writing Classes in the EFL Context: Students' Practices and Benefits. Arab World English Journal, 12 (2) 93-108. DOI: https://dx.doi.org/10.24093/awej/vol12no2.7
\end{abstract}




\section{Introduction}

In 2020, educational systems globally were forced to adapt and adopt remote teaching via online platforms to serve students due to the lockdowns initiated to limit the spread of COVID19. Since then, English language researchers in both Second Language (ESL) and Foreign Language (EFL) contexts have investigated the effects of the changes made on language learner's performance, attitudes, trajectories and overall learning progress (Al-Nofaie, 2020; Alahmad \& Alraddadi, 2020; Almelhi, 2021; Bailey, Almusharraf, \& Hatcher, 2020; Bin Dahmash, 2020a; Hashmi, Rajab, \& Ali Shah, 2021; Mahyoob, 2020; Shahzad et al., 2020; Syahrin \& Salih, 2020). This sudden essential switch to online classrooms changed educational policy in a number of countries, including Saudi Arabia. Previously, Saudi policymakers had not welcomed the option of teaching and learning 100\% online. Indeed, Saudi universities had suspended distance education in 2017, and so, during COVID-19 four universities were granted permission to provide distance programs ("After a hiatus of three years", 2020). Today, however, the Saudi Ministry of Education is considering continuing online classrooms after pandemic restrictions are lifted (Abueish, 2020).

Prior to the changes adopted as a result of COVID-19, language education researchers had asserted a need to explore the effectiveness and validity of virtual classrooms for teaching English (M. H. Al-Qahtani, 2019; M. S. Al-Qahtani, 2019). Therefore, unsurprisingly, many language researchers utilized the opportunities to collect additional data during the pandemic, to document and interrogate the learning styles of students in an online skill-based classroom (Syahrin \& Salih, 2020), highlighting the challenges encountered by students in synchronous classes, including technical problems and limited access to resources (Bin Dahmash, 2020a).

The focus of the present study is on synchronous and asynchronous classes; specifically the practices of EFL students in a Saudi university. It aims to scrutinize the benefits of classes from the perspectives of the students themselves. It poses the following questions:

1. What are the practices of students that emerge during synchronous and asynchronous English writing classes?

2. What are the benefits of synchronous and asynchronous English writing classes from the student's perspective?

\section{Definition of Practice}

The term 'practice' is defined in Merriam Webster Dictionary as "the usual way of doing something" ("practice", 2021). In this paper, 'practice' is used to refer to the conventional way in which students attend synchronous or asynchronous English writing classes and the activities and tools they utilize when engaging in these classes.

\section{Literature Review}

\section{Definitions of Synchronous and Asynchronous Classes}

The definitions of synchronous (in real-time) and asynchronous (at any time) classes are associated in the literature with online learning, blended learning, distance learning, virtual classes and e-learning. For example, Sharma and Westbrook (2016) mentioned 'synchronous' in reference to online and blended learning used in the field of language learning and technology. They identified an overlap between the two concepts, noting both refer to: 
[S]ituations where students are being taught synchronously using tools such as Skype, Adobe Connect, Wiziq Blackboard Collaborate -in effect, face to face learning at a distance-as well as situations that include anything that does not take place in the classroom. (Sharma \& Westbrook, 2016, p. 321)

This definition uses online and distance learning interchangeably to refer to situations where asynchronous real-time teaching mode is used outside the classroom via tools that enable the students to connect with the teacher via Internet, as in Blackboard Collaborate. However, the learning materials can also be posted on any online platform so students can access them asynchronously. Blended learning differs from online learning as it requires a physical place for conducting classes and disseminating learning content. If a course is conducted $100 \%$ online, it is "OL [online learning] not BL [blended learning]" (Sharma, 2017, p. 170). Mahyoob (2020) uses e-learning, virtual learning and online learning interchangeably to refer to various activities performed by language learners studying English via Internet platforms. These three terms referred to synchronized classes offered via Zoom, Google Classroom, Microsoft teams and Blackboard, as well as content posted on Blackboard. They also referred to the mode of sending and collecting assignments from students via WhatsApp groups or emails. Accordingly, all modes, whether synchronous or asynchronous involve online learning.

'Online' and 'e-learning' were used to refer to distance education when real-time sessions were taught via Blackboard or Zoom (Hashmi et al., 2021). The term 'virtual classes' was used to refer to classes 'synchronously' delivered, and when contacting students in real-time via Blackboard or Microsoft teams (Alahmad \& Alraddadi, 2020; M. S. Al-Qahtani, 2019). The realtime virtual classes via Blackboard Collaborate Ultra were described as synchronous classes, and were implemented to teach an intensive English course at King Saud University, while asynchronous classes refer to recorded synchronous classes (Bin Dahmash, 2020a). Similar to Bin Dahmash (2020a), Al-Nofaie (2020) used the terms synchronous referring to real-time classes and asynchronous to refer to the discussion board and assignments students accessed on Blackboard. The two concepts were not always treated as two distinct modes, and were used to describe the activities and videos that were delivered via virtual classes on Blackboard without making a distinction between these two concepts (Almelhi, 2021).

In this study, synchronous and asynchronous classes were defined as two distinct modes of distance learning where 100\% of classes were delivered online. Synchronous classes were English writing sessions delivered in real-time via Blackboard Collaborate Ultra. Asynchronous classes were recorded synchronous English writing sessions uploaded on Blackboard Collaborate Ultra to allow students to view content throughout the academic term.

\section{Online Learning During COVID-19}

Research into online ESL/EFL learning at the university level during COVID-19, whether synchronous or asynchronous, has attracted scholars interested in both language and pedagogy. In the Saudi context, several studies have explored the effects of online learning on students from either the students' or the teachers' perspectives, or both, during this period (Al-Nofaie, 2020; Alahmad \& Alraddadi, 2020; Almelhi, 2021; Bin Dahmash, 2020a; Hashmi et al., 2021; Mahyoob, 2020). In other countries, four studies were conducted on English language learners to understand online learning during the pandemic (Bailey et al., 2020; Ghounane, 2020; Shahzad 
et al., 2020; Syahrin \& Salih, 2020). These are explored in detail below to identify the focus for the current study.

In their research, Alahmad and Alraddadi (2020) examined the effects of virtual classes on classroom interaction in a university in Saudi Arabia during the pandemic. They used a questionnaire to elicit the views of 90 students studying an intensive English course. The interaction and participation of students in synchronous real-time class were examined. They found that virtual classes promoted interactions between the students themselves and between students and their teachers. Virtual classes were also found to encourage shy students to participate in classroom discussions and to assist them in overcoming their anxiety and improving their language skills.

Applying a case study methodology, Al-Nofaie (2020) elicited the opinions of 25 students concerning the benefits and problems experienced using the synchronous and asynchronous features of Blackboard at a Saudi university during the pandemic. Her participants studied in the English language department, received a Morphology course via synchronous lectures on Blackboard and used learning materials posted asynchronously on Blackboard. She also analyzed students' learning logs. She discovered that students favored asynchronous features over synchronous ones due to their flexibility and reported encountering difficulties focusing on lectures at home due to distractions. She also found asynchronous features helped shy students participate via text on the discussion board, thereby improving their language skills.

The benefits and challenges of online learning were further explored in a qualitative study conducted by Bin Dahmash (2020a) in a Saudi university. She examined the use of synchronous virtual lectures, online tests and educational content posted via Blackboard for an intensive English course available during COVID-19. The study involved a focus group and one-to-one interviews with twelve students. Synchronous classes were found to support students' English writing skills by offering tasks focused on spelling and grammar. Students were motivated to search online via Google and YouTube to supplement their English learning and the classes were suited to students' needs and circumstances as well as their family responsibilities. The students reported encountering technical problems that impeded their understanding, such as sound problems and internet connection issues.

In 2020, Mahyoob explored the obstacles and challenges encountered when implementing online learning during COVID-19 from the perspective of students majoring in the English language at a Saudi university. He collected data from 184 students with a questionnaire and identified that they had technical difficulties accessing virtual classes on Blackboard and expressed a preference for other platforms. According to Hashmi et al. (2021), who used questionnaires to collect the views of 265 language teachers at four universities; $80 \%$ of teachers used Blackboard to teach using a synchronous lecturing mode during the pandemic, and observed students reported limited access due to technical problems. Students were not trained in online learning and claimed to miss the classroom interaction, and found it difficult navigating online and accessing the materials posted there. Their students were also increasingly disappointed and demotivated to learn English. 
The role of Blackboard in delivering English courses was explored by Almelhi (2021). To accomplish this goal, he measured the attitudes and perceptions of 47 EFL instructors and 103 students taking English courses at King Khalid University, applying quantitative methods. He designed two questionnaires and distributed them, one for instructors and the other for students. He found that the students perceived Blackboard to be a cost-saving and time-saving tool and an efficient tool for communication. He also found that Blackboard motivated students to learn English and assisted them in self-pacing their language learning. He asserted:

[T] he most common reasons students liked the VLE of Blackboard could be convenience of use, platform availability, system quality and quality of e-learning over Blackboard. Other reasons include users' personal factors such as their satisfaction tendency, their selfconfidence initiated by the VLE of Blackboard, their enjoyment of learning in this medium, the interesting and useful learning activities and tools as well as their staying safe in this mode of learning in the pandemic time. (Almelhi, 2021, p. 60)

In a study by Bailey et al. (2020) conducted at a South Korean university, students' intrinsic motivation during collaborative asynchronous writing practice and synchronous video speaking practice via an online course were explored. Their study drew on a quantitative methodology and distributed a cross-sectional survey to 186 students and an open-ended survey to 65 students. Asynchronous writing classes were found to assist students in learning new vocabulary, increase their opportunities to practice writing and develop their skills in English grammar. Moreover, synchronous video-speaking practice assisted students in communicating with their classmates and their instructors, improved their pronunciation and conversation skills, and increased their confidence when speaking English.

In the context of an Algerian university, Ghounane (2020) examined e-learning in the form of virtual learning via Zoom, Google Classroom and Moodle and the learning tools EFL students were engaged in during COVID-19. The research involved 90 students who completed a questionnaire and eight teachers who were interviewed. The students reported a preference for Moodle as a formal setting to attend lectures and engage in activities. In addition, students used Facebook and YouTube to interact with teachers and classmates. A questionnaire was also used by Shahzad et al. (2020) to elicit the views of 100 students at a Pakistani university. They evaluated the effect of virtual teaching during COVID-19 on English language learners' attitudes. The students were committed and motivated to learn via virtual learning settings; they found virtual lectures convenient, and were able to communicate with their teacher via voice and text to receive a quick reply. The research also revealed that virtual learning boosted students' confidence and happiness and relieved frustration and worry. At an Omani university, Syahrin and Salih (2020) used a questionnaire combined with content and course activities analysis to evaluate the success of asynchronous online learning. They investigated the experiences of 32 students accessing online classrooms via Moodle (a learning management system) during the pandemic. They concluded that online learning mainly benefits listening and reading skills and neglects speaking and writing skills.

The studies by Al-Nofaie (2020), Alahmad and Alraddadi (2020), Bailey et al. (2020), Mahyoob (2020), Syahrin and Salih (2020), Almelhi (2021), and Ghounane (2020) utilized quantitative tools (i.e. a questionnaire) and did not interview students. The participants were asked to rate statements based on a five point Likert-scale. In addition, the studies by Al-Nofaie (2020), Alahmad and Alraddadi (2020), Bailey et al. (2020), Mahyoob (2020), Shahzad et al. 
(2020), Syahrin and Salih (2020) and Bin Dahmash (2020a) did not ask students about their personal practices, or the activities they engage in when attending synchronous virtual live classes. Therefore, the current study offers unique and valuable insights by drawing on group interviews and one-to-one interviews to explore the practices of university students attending synchronous classes.

The learning described in the above studies was not $100 \%$ online, as these started partially or fully as a face-to-face language learning classes and moved online in response to COVID-19 restrictions. The students therefore had met their classmates and their teacher in person, and had attended some classes physically. In addition, these studies did not explore asynchronous classes based on recordings of synchronous sessions, and the perspectives of language learners were not examined. However, Almelhi (2021) reported that $93 \%$ of students participating in virtual classes on Blackboard preferred synchronous classes to recorded ones but did not explore this result in interviews. The current study addresses these gaps by examining classes where $100 \%$ of learning was delivered online, and explores the benefits and practices engaged in by students in asynchronous classes.

\section{Methodology}

This study drew on a qualitative research methodology in the domain of Applied Linguistics, using 'narrative inquiry' to 'document language learners' and teachers' development, practices, identity, agency, beliefs, emotion, positionality, and motivation" (Lew et al., 2018, p. 88). Interviews are helpful for collecting in-depth data about participant's experiences (Kvale, 1996; Kvale \& Brinkmann, 2009) and group interviews are valuable:

[W] hen the researcher seeks to elicit a range of responses to produce a more holistic picture of a group's or community's (shared and divergent) perspectives on their sociolinguistic experiences, perspectives, resources, practices, and so on. (Prior, 2018, p. 234)

Thus, one-to-one and group interviews were used to generate a comprehensive picture of the practices of students engaged in synchronous and asynchronous English writing classes, and to collect their perspectives concerning these two modes.

\section{Research Procedures}

Data were collected in two stages commencing at the end of December 2020 and lasting for seven weeks. The first stage involved conducting two group interviews, and the second stage the one-to-one interviews. Data were collected during the COVID-19 pandemic when meeting people physically was only possible if following precautionary measures such as wearing face masks and repeatedly sterilizing surfaces and hands. Therefore, all interviews, whether group or one-to-one, were conducted online via a platform selected by the participants. Group interviews were completed on WhatsApp groups in two sessions: six participants each. One-to-one interviews were completed involving eleven participants over WhatsApp.

\section{Participants}

Participants were recruited via a sampling process referred to as 'chain sampling' (Dörnyei, 2007). The participants were recruited by the researcher, who contacted a key participant who then invited other participants to join the study. Participants were selected 
according to sampling criteria; i.e., they had to have recently completed an English writing course in a department in which the course was delivered synchronously and asynchronously as part of departmental policy. All the participants received an information text message via WhatsApp detailing the study aims, tools, and their right to withdraw from the sample at the time of data collection without providing reasons, also reiterating that participation is voluntary. The participants were twelve female students majoring in computer science and information technology at a Saudi university.

\section{Data Analysis}

The study drew on Ayres's (2008) thematic coding and thematic analysis. The data analysis process was aided by ATLAS.ti, a computer software designed for data analysis to enhance validity (Cohen et al., 2018). The software assisted the researcher in maintaining consistency and reliability when coding the data (Creswell, 2014). Lists of themes were created after coding the interviews to answer the two research questions.

\section{Results and Discussion}

This section presents and discusses the results from the current study in relation to the research questions and the previous literature.

\section{Research Question (1): What Are the Practices of Students that Emerge during Synchronous and Asynchronous English Writing Classes?}

The data suggests students engage in various practices when attending both synchronous and asynchronous English writing classes. These involve English writing class modes as one practice occurred in the synchronous class only and another practice occurred in the asynchronous class only (see Figure.1).

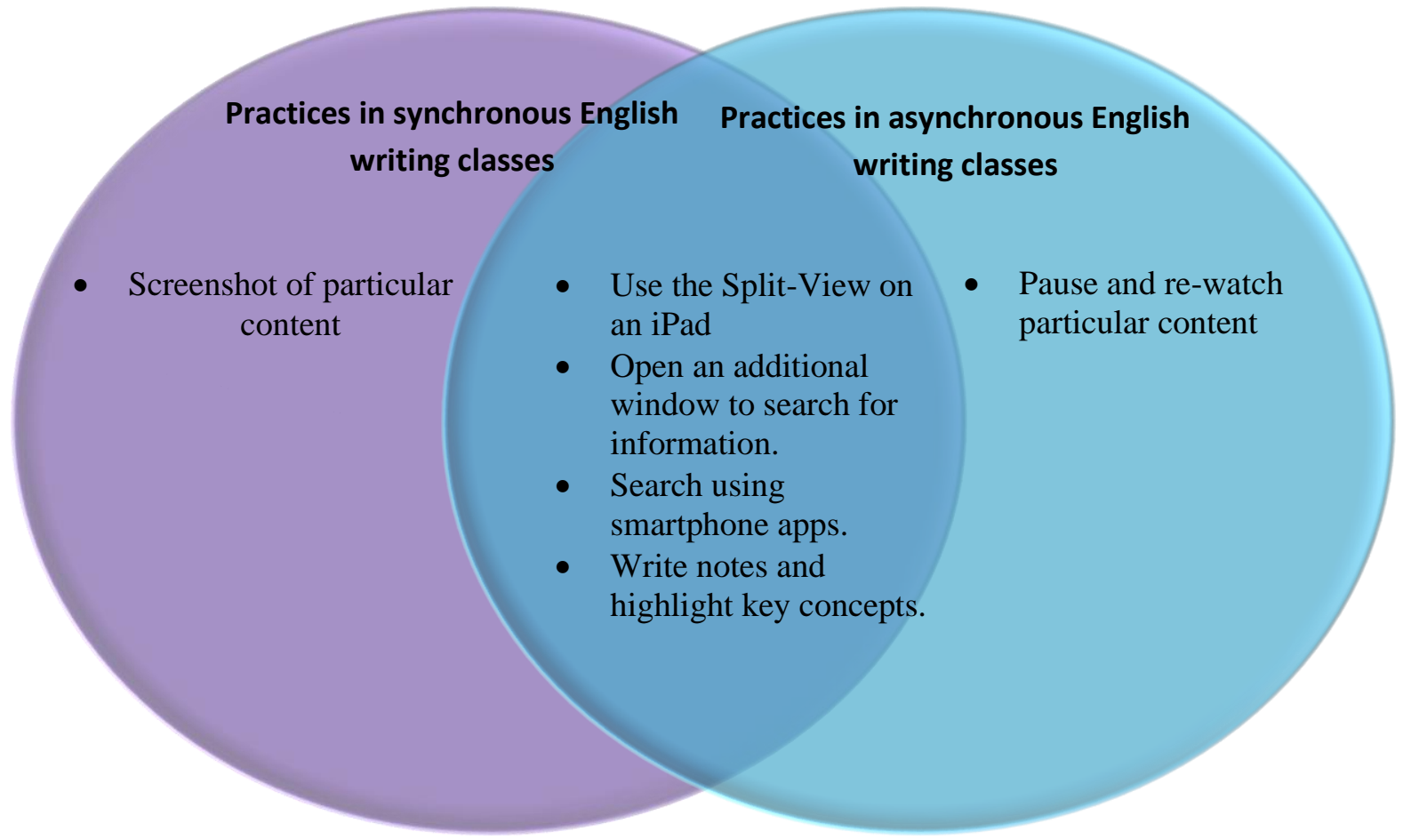

Figure 1. Practices on synchronous and asynchronous English writing classes 


\section{Practices Shared on Synchronous and Asynchronous English Writing Classes}

The students reported that they engage in multiple practices when attending English writing classes regardless of mode. These practices were: (1) use the split view on an iPad, (2) open an additional window to search for information, (3) search using smartphone apps, and (4) write notes and highlight key concepts.

\section{Use the Split View on an iPad}

Attending English writing classes from the iPad provided participants with the ability to use a feature called Split View. Split View allows iPad users to view two different apps by splitting the iPad screen equally into two parts separated by a bold vertical line. This allows the iPad user to view two windows on one screen simultaneously. Participant (12) reported that she prepares her iPad before class by opening two iPad apps: Safari and Pdf Reader. She clarified that she watches English writing classes on Blackboard Collaborate Ultra in one view, and uses the other view to add notes and highlight concepts using an Apple pencil. She stated, "I use the other view as if I was using a real pen and paper". Another participant, participant (3), reported using Split View allowed her to attend the class and see the required textbook simultaneously. She stated, "the first view is more like attending the face-to-face class and the second view is more like following what the teacher says on a real book in a real class". It seems the Split-View iPad feature provided participants with an innovative learning option, enabling them to develop new practices inspired by their past experience in attending face-to-face classes. They visualized attending a face-to-face class in one view and writing notes and highlighting concepts in a book on the other view.

Open an Additional Window to Search for Information

Attending English writing classes from a computer or laptop allowed participants to open an additional window when searching for particular information. Participants in group interview (2) explained that they open a new window frequently when attending English writing classes, whether synchronous or asynchronous classes. Participant (8) explained she does this when requiring further information related to the course. She stated, "I listen to the class and search for particular information at the same time to fully understand the content when I don't understand the teacher". Participants in a group interview (1) reported using search engines such as Google to gather information, even when redirected to YouTube. Using YouTube to search for information is consistent with results reported by Bin Dahmash (2020a), who found that students were motivated to search via YouTube after trying out synchronous classes and corresponds with the results of Bin Dahmash (2021) regarding the practices language learners were engaged in during the COVID-19 crisis in Saudi Arabia.

\section{Search Using Smartphone Apps}

Among the practices, students reported engaging in while attending English writing classes were searching using two smartphone apps: Google and Google Translate.

Participants in group interview (1) reported searching using the Google app on their smartphones during English writing classes. Participant (3) stated, "I opened Google app and typed how to summarize a text when I was listening to the teacher explaining writing summaries". She explained that summarizing material in English was challenging, and she wanted to learn an easier way to complete this task. 
The majority of the participants reported using the Google Translate App to discover the meaning of words and phrases in Arabic.

[04/01/2021, 9:26:11 pm] Researcher:

[04/01/2021, 9:27:36 pm] Participant (11):

[04/01/2021, 9:27:52 pm] Participant (9):

[04/01/2021, 9:28:00 pm] Participant (10):

[04/01/2021, 9:28:39 pm] Researcher:

[04/01/2021, 9:28:50 pm] Participant (10):

[04/01/2021, 9:29:00 pm] Participant (11):

[04/01/2021, 9:29:01 pm] Participant (9):

[04/01/2021, 9:29:09 pm] Participant (7):

[04/01/2021, 9:29:13 pm] Participant (8):
You mentioned you use the Google

Translate App. Can you explain further?

The biggest barrier on this course is the language and I needed to search for the meaning of some words from English to Arabic

Agree. This course needs someone who has mastered English

This is why I always use Google Translate

App.

During the live session or recorded session?

Doesn't matter, any session.

Me too.

Same.

I am used to doing this. Open my phone and type the words I don't understand I take a photo of the screen to translate the text instantly

(Excerpt from group interview (2) translated from Arabic)

This excerpt demonstrates that students utilize the Google Translate App to identify the meaning of unfamiliar English words in both English writing classes. Participant (4) reported that her English is weak, and that she hoped to get high grades for her English writing course and used the Google Translate App to assist her. She stated, "this translates superfast. I don't waste my time and type... I just take a photo and all the text is translated from English to Arabic".

The students' practices using the App seem to be triggered by their aspiration to improve their English, as they are majoring in computer science. They expressed a need and desire to excel in English writing and develop their skills in computing, as all the resources and highquality papers in their field were in English. They used the Google Translate App as a tool to boost their understanding of key concepts and to internalize learning content. This result confirms the findings reported in previous studies (Alhaisoni \& Alhaysony, 2017; Bin Dahmash, 2020b; Bin Dahmash, 2021; Tsai, 2019) stating that using the Google Translate App enhances learners' capacity in English.

\section{Write Notes and Highlight Key Concepts}

Writing notes and highlighting key concepts were among the practices students engaged in when attending English writing classes. These practices were carried out in paper format and digital format.

The majority of the participants in group interview (1) reported downloading and printing the PowerPoint slides posted on the Blackboard platform before the live session, so as to write 
notes and the dates on them. Participant (4) indicated that she writes the dates on slides to assist her in locating asynchronous sessions to continue writing notes. She stated, "writing the date helped me in finding the recorded session. They were arranged according to date and I watched the recorded session to write the notes". Participant (1) explained that writing notes on a paperformat (whether on the textbook or printed slides) assisted her in understanding key concepts during classes, as well as assisted her in focusing on improving her English writing. Similarly, participant (2) explained that before synchronous classes, she prepares her environment, ensuring she has materials and tools ready; i.e. textbooks, printed slides, pens, and highlighters. She indicated that writing notes on paper reinforces her understanding of writing skills in English, and helps her focus on her goal of "making my English writing better".

Producing notes in a digital format was reportedly among practices that were engaged in during English writing classes. Participant (3) explained that she uses the Note App on her smartphone to write notes during classes as she does not like touching papers. She clarified that she selects English letters from the touch keypad on her smartphone. Participant (12) reported a similar practice using the Note App on her smartphone, which automatically synchronizes to her Note App on her iPad. She explained that she does not transfer what she has written on her smartphone as the technology does that for her. Participant (12) also reported adding notes to the textbook via the Pdf Reader App using an Apple pencil. She highlights parts of the textbook and uses different highlighting colors on the App, stating, "I use the Apple pencil on iPad and normally write on smartphone". These accounts of writing notes in a digital format reflect the students' creative use of technology, especially multitasking with ease and confidence. From their accounts, they did not express feeling overwhelmed or being stressed when performing multiple entangled practices digitally.

\section{Synchronous English Writing Classes Practice: Screenshot Particular Content}

Taking a screenshot of valuable content was mentioned only in reference to the synchronous English writing classes. In group interview (2), the participants explained that they screenshot during live sessions, as they cannot quickly write what is on the slides, especially when the teacher uses a different PowerPoint presentation. Participant (2) indicated that she keeps screenshots in a separate file on her computer and prints them out when studying for exams. Participant (7) reported taking screenshots to enable her to write notes after the session and to delete the screenshot after that. She stated, "I don't want to confuse myself, so I write the notes and then delete these screenshots". This indicates that participants perform the practice of screenshots during synchronous classes, but differ in how they deal with them. Some print them out and use them as a source of learning, while others keep them for a limited time.

\section{Asynchronous English Writing Classes Practice: Pause and Re-watch Particular Content}

Pausing and re-watching particular content only took place in the asynchronous class. The participants indicated that the ability to pause and watch certain parts was what distinguishes recorded sessions from live ones. All the participants mentioned performing the practice of pausing and re-watching classes whenever they played recorded sessions.

Research Question (2): What are the Benefits of Synchronous and Asynchronous English Writing Classes from the Students' Perspective? 
The data suggests that attending both synchronous and asynchronous English writing classes enabled students to benefit from both. This section discusses these benefits separately (see Figure. 2).

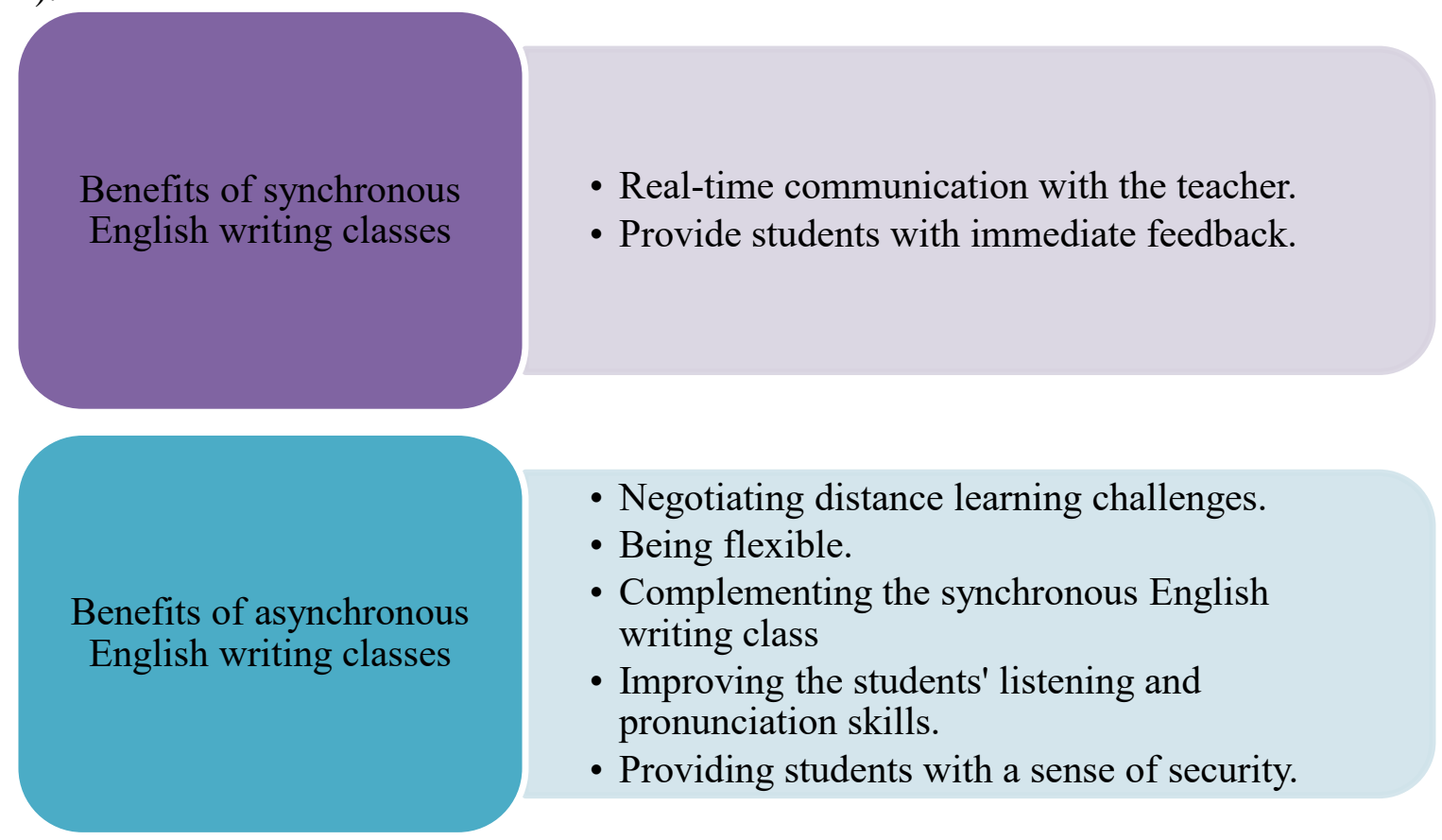

Figure 2. Benefits of synchronous and asynchronous English writing classes Benefits of Synchronous English Writing Classes

The data suggests the advantages of synchronous classes were real-time communication and the provision of immediate feedback. The participants in group interview (2) explained synchronous classes were interactive, enabling them to communicate their questions regarding lesson content and to receive an immediate answer. They observed that having the opportunity to ask questions verbally by turning their mics on, or posting questions in the chat box in writing saves time when communicating with teachers in real-time. Participant (5) asserted that live sessions facilitate communication with the teacher, and that without them she would have to compose an email containing questions and wait for the teacher to reply. This is consistent with the results reported by Shahzad et al. (2020), Bailey et al. (2020), and Almelhi (2021), who found virtual synchronous classes helped students communicate with their teachers. It is also consistent with the results reported by Ja'ashan (2020), who found e-learning enhanced students' communication. It contradicts the findings of M. S. Al-Qahtani (2019), who reported that students had limited communications with both their teacher and classmates, as attending virtual classes isolated them from the outside world.

Besides providing real-time communication with the teacher, synchronous classes afforded students immediate feedback. Participant (2) indicated that live sessions offered her opportunities to check her understanding and receive instant feedback at the end of classes. According to her, instant feedback increased her motivation and encouraged her to learn. The participants in group interview (1) noted that rapid feedback is essential and only happens during live sessions. This 
result echoed the findings reported by Al Bataineh, Banikalef, and Albashtawi (2019), that blended learning ensures immediate feedback.

\section{Benefits of Asynchronous English Writing Classes}

The students listed five benefits of asynchronous writing classes, outnumbering the benefits of the synchronous classes. First, asynchronous classes assisted students in negotiating distance learning challenges such as: 1) technical problems, and 2) the inability to separate between the learning environment and the home environment. The participants in group interview (2) indicated that the recorded sessions were beneficial when their internet connection was intermittent and the sound unclear. Similarly, participant (4) stated that sometimes she encounters technical problems, such as a poor Internet connection, or a power cut, and so the recorded session provides useful back up. The majority of participants found separating the learning environment and home environment challenging. Participant (1) mentioned family responsibilities; she is a mother and has a daughter who studies online during her live sessions and sometimes she has to check if her daughter is following along with her classes. She stated, "the recorded session solved crisis as I often stop for a few minutes to see if my daughter who is in primary stage is doing fine with her online school". Participant (9) indicated that focusing during the live session was difficult, as being at home prevents her from controlling what happens around her, and so the recorded session bridges any gaps. Thus, asynchronous sessions resolve the difficulties identified by Bin Dahmash (2020a), Hashmi et al. (2021), Al-Nofaie (2020) and Mahyoob (2020), who reported that synchronous classes during COVID-19 were disadvantaged by technical and social challenges.

The second benefit mentioned was flexibility, as the participants in group interview (1) mentioned being able to watch recorded sessions from anywhere at any time; some stated that they would record the sessions themselves if the university stopped uploading asynchronous classes. Participant (2) indicated that she sometimes watches the session repeatedly focusing on certain parts until she has fully absorbed the content. The flexibility and convenience asynchronous lectures provide to students correspond with the results reported by Bukhari and Basaffar (2019), Shahzad et al. (2020), Al Bataineh, Banikalef, and Albashtawi (2019), Al-Nofaie (2020), Bin Dahmash (2020a) and Almelhi (2021), who found learning via online virtual settings was convenient and flexible.

Complementing the synchronous writing classes was reported as one of the benefits of asynchronous writing classes.

[28/12/2020, 4:54:13 pm] Participant (2):

[28/12/2020, 4:54:32 pm] Participant (3):

[28/12/2020, 4:54:47 pm] Participant (1):

[28/12/2020, 4:55:00 pm] Participant (2):
With all the assignments I cannot focus during the live sessions, but still the live sessions are important.

Homework and live sessions take the entire day literally! I am left with no mind at all and sometimes I cannot understand during the live sessions.

Agree. Can you imagine spending 4 hours a day attending live sessions, let alone homework, midterm studies, family obligations.

I try to focus on the live sessions, but I cannot always succeed ... and I watched the 
[28/12/2020, 4:55:08 pm] Participant (1): [28/12/2020, 4:55:09 pm] Participant (3): [28/12/2020, 4:55:47 pm] Participant (1):

[28/12/2020, 4:56:02 pm] Participant (4): [28/12/2020, 4:56:26 pm] Researcher:

[28/12/2020, 4:56:58 pm] Participant (2): [28/12/2020, 4:57:03 pm] Participant (1): [28/12/2020, 4:57:09 pm] Participant (3): [28/12/2020, 4:57:13 pm] Participant (6): recorded session to catch up with what I had missed, even when I was there in person. This is one of the advantages of recorded sessions.

Me too.

Agree.

I go back to the recorded session to compensate for what I missed.

I watch the parts I did not understand.

Can I say that the recorded session completes the live session, do you think the recorded one replaces the live ones?

Does not replace! Completes them. Completes Agree completes.

Me too - completes.

(Excerpt from group interview (1) translated from Arabic)

This excerpt demonstrates how asynchronous classes complement synchronous classes by giving participants an additional opportunity to comprehend lesson content. They explained that asynchronous classes are not seen as a substitute for synchronous classes but as a valuable supplement. Participant (12) indicated that accessing recorded sessions allowed her to fulfil her learning objectives by filling in details missed during synchronous classes.

The fourth benefit of asynchronous writing classes is in improving students' listening and pronunciation skills. Participant (4) reported that she repeatedly watched the recorded session to imitate her teacher's pronunciation of English words. Participant (7) indicated that playing the recorded session improved her listening skills, as she could listen several times to difficult parts. This benefit correlates with the findings of M. S. Al-Qahtani (2019), Al-Nofaie (2020), Alahmad and Alraddadi (2020), Bailey et al. (2020) and Bin Dahmash (2020a), that language learning online via virtual classes enhanced students' English language skills.

The last benefit reported was the sense of security asynchronous sessions provide. Participant (3) noted that she feels reassured by having recorded sessions uploaded on Blackboard, even if she does not always review them. The participants in group interview (1) agreed, indicating that they watch the recorded sessions before exams and assignments to reinforce what they have learnt, and that this option improves their confidence. Thus, the asynchronous classes enhanced the students' comfort levels and reduced anxiety. This finding suggests they could reduce the "affective filter" identified by Krashen (1981), when linking anxiety and negative feelings on the part of learners to difficulty in learning an additional language.

\section{Conclusion and Implications}

The students engaged in multiple practices in both English writing class modes, synchronous and asynchronous. For example, using the split view on their iPads, opening an additional window to search for information, searching using smartphone Apps, and writing notes and highlighting key concepts. They only screenshotted particular content during 
synchronous classes, and they paused and re-watched content during asynchronous classes. These practices were creative and reflected the student's proficiency with technology. The benefits of the synchronous class were fewer than the benefits of the asynchronous ones according to the students. The primary benefit of synchronous classes was that they offer realtime communication and provide them with access to immediate feedback. The asynchronous class, on the other hand, benefited students by assisting them in coping with various distance learning challenges, being flexible, complementing the synchronous English writing class, improving their listening and pronunciation skills, and providing them with a sense of security.

Based on these findings, a number of implications were proposed to improve the process of language learning in synchronous and asynchronous classes. Teachers were advised to record synchronous classes based on the benefits reported in this study and to upload these classes to the online learning system approved by the institution at which the classes were being taught. The teachers then could advise their students to watch the asynchronous classes and explain to them the benefits reported by students, as well as motivating them to watch and boost their language capacity. The teachers could also encourage the students to apply the practices reported in this study when searching for related learning content via smartphone Apps or websites. Policymakers could encourage teachers to record sessions and offer them incentives. The students were advised to prepare the physical environment in which they attend synchronous classes to eliminate distractions.

\section{About the Author}

Nada Bin Dahmash is an assistant professor at King Saud University, Riyadh, Saudi Arabia. She obtained her PhD degree in 2019 from the Department of Linguistics and English Language at Lancaster University, United Kingdom. She is interested in second language practices, use of English outside the classroom, online learning and the effects of technology on language learning. https://orcid.org/0000- 0001-5918-5124

\section{References}

Abueish, T. (2020, September 21). Distance Learning in Saudi Arabia May Continue even after Coronavirus: Minister. AlArabiya News. Retrieved March 1, 2021 from https://ara.tv/586k6

After a Hiatus of Three Years, 4 Universities Obtain License for Distance Education. (2020, December 1). Saudi Gazette. Retrieved March 1, 2021 from https://saudigazette.com.sa/article/600927

Al Bataineh, K. B. A., Banikalef, A. e. A. A., \& Albashtawi, A. (2019). The Effect of Blended Learning on EFL Students' Grammar Performance and Attitudes: An Investigation of Moodle. Arab World English Journal, 10(1), 324-334. http://dx.doi.org/10.2139/ssrn.3367595

Al-Nofaie, H. (2020). Saudi University Students' Perceptions towards Virtual Education During Covid-19 Pandemic: A Case Study of Language Learning via Blackboard. Arab World English Journal, 11(3), 4-20. https://dx.doi.org/10.24093/awej/vol11no3.1

Al-Qahtani, M. H. (2019). Teachers' and Students' Perceptions of Virtual Classes and the Effectiveness of Virtual Classes in Enhancing Communication Skills. Arab World English Journal, 1(Special Issue: The Dynamics of EFL in Saudi Arabia), 223-240. https://doi.org/10.24093/awej/efl1.16 
Al-Qahtani, M. S. (2019). The Relevance of Doing Virtual Classes: A Study of Postgraduate Female Students' Attitudes and Perceptions. Arab World English Journal(1), 188-206. https://doi.org/10.24093/awej/efl1.14

Alahmad, N. S., \& Alraddadi, B. M. (2020). The Impact of Virtual Classes on Second Language Interaction in the Saudi EFL Context: A Case Study of Saudi Undergraduate Students. Arab World English Journal, 11(3), 56-72. https://dx.doi.org/10.24093/awej/vol11no3.4

Alhaisoni, E., \& Alhaysony, M. (2017). An Investigation of Saudi EFL University Students' Attitudes towards the Use of Google Translate. International Journal of English Language Education, 5(1), 72-82. https://doi.org/10.5296/ijele.v5i1.10696

Almelhi, A. M. (2021). The Role of the Blackboard LMS in EFL Course Delivery During the COVID-19 Pandemic: Investigating Attitudes and Perceptions of Faculty and Students. International Journal of English Linguistics, 11(2), 46-67. https://doi.org/10.5539/ijel.v11n2p46

Ayres, L. (2008). Thematic Coding and Analysis. In L. M. Given (Ed.), The SAGE Encyclopedia of Qualitative Research Methods (Vol. 2, pp. 868). Thousand Oaks: Sage Publications.

Bailey, D., Almusharraf, N., \& Hatcher, R. (2020). Finding Satisfaction: Intrinsic Motivation for Synchronous and Asynchronous Communication in the Online Language Learning Context. Education and Information Technologies, 1-21. https://doi.org/10.1007/s10639-020-10369-z

Bin Dahmash, N. (2021). 'We Were Scared of Catching the Virus': Practices of Saudi College Students During the COVID-19 Crisis. International Journal of English Linguistics, 11(1), 152-165. https://doi.org/10.5539/ijel.v11n1p152

Bin Dahmash, N. (2020a). 'I Couldn't Join the Session': Benefits and Challenges of Blended Learning amid COVID-19 from EFL Students. International Journal of English Linguistics, 10(5), 221-230. https://doi.org/10.5539/ijel.v10n5p221

Bin Dahmash, N. (2020b). 'I Can't Live Without Google Translate': A Close Look at the Use of Google Translate App by Second Language Learners in Saudi Arabia. Arab World English Journal, 11(3), 226-240. https://doi.org/10.24093/awej/vol11no3.14

Bukhari, S. S. F., \& Basaffar, F. M. (2019). EFL Learners' Perception about Integrating Blended Learning in ELT. Arab World English Journal, 5(1), 190-205. https://doi.org/10.24093/awej/call5.14

Cohen, L., Manion, L., \& Morrison, K. (2018). Research Methods in Education (8 ${ }^{\text {th }}$ ed.). London: Routledge.

Creswell, J. W. (2014). Research Design : Qualitative, Quantitative, and Mixed Methods Approaches (4th ed.). Thousand Oaks: Sage Publications.

Dörnyei, Z. (2007). Research Methods in Applied Linguistics : Quantitative, Qualitative and Mixed Methodologies. Oxford: Oxford University Press.

Ghounane, N. (2020). Moodle or Social Networks: What Alternative Refuge is Appropriate to Algerian EFL Students to Learn during Covid-19 Pandemic. Arab World English Journal, 11(3), 21-41. https://doi.org/10.24093/awej/vol11no3.2

Hashmi, U. M., Rajab, H., \& Ali Shah, S. R. (2021). ELT During Lockdown: A New Frontier in Online Learning in the Saudi Context. International Journal of English Linguistics, 11(1), 44-53. https://doi.org/10.5539/ijel.v11n1p44 
Ja'ashan, M. M. N. H. (2020). The Challenges and Prospects of Using E-learning among EFL Students in Bisha University. Arab World English Journal, 11(1), 124-137. https://doi.org/10.24093/awej/vol11no1.11

Krashen, S. (1981). Second Language Acquisition and Second Language Learning. Oxford: Pergamon Press.

Kvale, S. (1996). InterViews : An Introduction to Qualitative Research Interviewing. Thousand Oaks, Calif: Sage Publications.

Kvale, S., \& Brinkmann, S. (2009). Interviews: Learning the Craft of Qualitative Research Interviewing $\left(2^{\text {nd }}\right.$ ed.). Thousand Oaks, Calif: Sage Publications.

Lew, S., Yan, A. H., \& Harklau, L. (2018). Qualitative Methodology. In A. Phakiti, P. De Costa, L. Plonsky, \& S. Starfield (Eds.), The Palgrave Handbook of Applied Linguistics Research Methodology (pp. 79-101). London: Palgrave Macmillan UK.

Mahyoob, M. (2020). Challenges of e-Learning during the COVID-19 Pandemic Experienced by EFL Learners. Arab World English Journal, 11(4), 352-362. https://doi.org/10.24093/awej/vol11no4.23

Practice. (2021). In Marriam Webster Dictionary. Retrieved March 1, 2021 from https://www.merriam-webster.com/dictionary/practice

Prior, M. T. (2018). Interviews and Focus Groups. In A. D. C. Phakiti, Peter. Plonsky, Luke. Starfield, Sue. (Ed.), The Palgrave Handbook of Applied Linguistics Research Methodology (pp. 225-248). London: Palgrave Macmillan UK.

Shahzad, S. K., Hussain, J., Sadaf, N., Sarwat, S., Ghani, U., \& Saleem, R. (2020). Impact of Virtual Teaching on ESL Learners' Attitudes under Covid-19 Circumstances at Post Graduate Level in Pakistan. English Language Teaching, 13(9), 1-9. https://doi.org/10.5539/elt.v13n9p1

Sharma, P. (2017). Blended Learning Design and Practice. In M. Carrier, R. M. Damerow, \& K. M. Bailey (Eds.), Digital Language Learning and Teaching: Research, Theory, and Practice (pp. 167-178). New York: Routledge.

Sharma, P., \& Westbrook, K. (2016). Online and Blended Language Learning Book. In F. Farr \& L. Murray (Eds.), The Routledge Handbook of Language Learning and Technology (pp. 320-334). New York: Routledge.

Syahrin, S., \& Salih, A. A. (2020). An ESL Online Classroom Experience in Oman During Covid-19. Arab World English Journal, 11(3), 42-55. https://doi.org/10.24093/awej/vol11no3.3

Tsai, S.-C. (2019). Using Google Translate in EFL Drafts: a Preliminary Investigation. Computer Assisted Language Learning, 32(5-6), 510-526. https://doi.org/10.1080/09588221.2018.1527361 